\title{
Cost-effectiveness and equitable access to vaccines in Ethiopia: an overview and evidence synthesis of the published literature
}

\author{
Solomon T Memirie' ${ }^{1}$, Mulat Nigus'², Stéphane Verguet ${ }^{3}$ \\ ${ }^{1}$ Department of Pediatrics and Child Health, College of Health Sciences, Addis Ababa University, Addis Ababa, Ethiopia, 2 Federal Ministry of Health \\ Ethiopia, Addis Ababa, Ethiopia, ${ }^{3}$ Department of Global Health and Population, Harvard T.H. Chan School of Public Health, Boston, Massachusetts, \\ USA \\ Keywords: vaccine-preventable diseases, ethiopia, health financing \\ https://doi.org/10.29392/001c.19354
}

Journal of Global Health Reports

Vol. 5, 2021

In Ethiopia, despite the introduction of new vaccines and a steady increase in access to immunization services over the last decade, considerable coverage gaps have persisted leading to a heavier vaccine-preventable disease (VPD) burden among poorer households. In this paper, we present a brief overview including available evidence and published studies on vaccine economics in Ethiopia, covering the topics of cost-effectiveness analysis, cost of illness associated with VPDs, equitable access to vaccines, and immunization financing. We can then point that large disparities in vaccine access exist by geographic location, socioeconomic and maternal educational status. Ethiopian households, especially the poorest, can incur impoverishing out-of-pocket expenditures for VPDs. Financing for immunization services has shown modest improvements in Ethiopia over recent years prior to the COVID-19 pandemic. A number of economic evaluation studies have pointed to the potentially pro-poor benefits of immunization programs in Ethiopia, yielding health and financial risk protection gains among the poorest households.

Immunization is recognized as a core component of human rights to health. ${ }^{1}$ It can prevent a few million deaths worldwide every year, and it is one of the most cost-effective public health interventions. ${ }^{1}$ Globally, in recent years, access and use of vaccines have progressively expanded, and several new vaccines have been introduced (e.g. rotavirus, pneumococcal conjugate vaccines). Yet, despite impressive progress over the past two decades, immunization coverage gaps have persisted between and within countries, across geographic locations and socioeconomic status (e.g wealth, education). ${ }^{2-4}$ Underserved populations often carry a heavier vaccine-preventable disease (VPD) burden, lack access to basic health care, and are more likely to be pushed into poverty due to out-of-pocket (OOP) medical expenditures. ${ }^{4}$

In Ethiopia, a low-income country with the second largest population in Africa, ${ }^{5}$ the Expanded Programme on Immunization (EPI) was initiated in 1980 with six antigens against common childhood diseases: diphtheria, pertussis, tetanus (DPT vaccine); tuberculosis (Bacille CalmetteGuérin or BCG); poliomyelitis (oral polio vaccine or OPV) and measles (measles-containing vaccine or MCV). ${ }^{6}$ In the last decade, more antigens were included: Haemophilus influenzae type B (HiB vaccine), hepatitis B (HepB vaccine), pneumococcal conjugate vaccine (PCV), rotavirus vaccine (RV), and human papillomavirus (HPV) vaccine. ${ }^{7}$ As a result, immunization coverage has progressively increased (see evolution over $2000-2019$ on Figure 1 ) $;^{2,8-11}$ however, there remains a substantial coverage gap in the country. For instance, coverage of the third dose of DPT-hepB-Hib vaccine (here referred to as Penta 3 ) and first dose of measles vaccine (MCV1) were only 61 and 59\%, respectively, in $2019,{ }^{2}$ which is far lower than the $80 \%$ target set by the national health plan, the so-called Health Sector Transformation Plan 2016-2020. ${ }^{12}$ In fact, Ethiopia was among the six countries with the greatest number of unvaccinated infants in 2018 (next to Nigeria, India and Pakistan): 1.3 million infants would not receive MCV1 via the routine immunization program. ${ }^{13}$ Several factors could limit access to immunization services in Ethiopia such as family awareness of the need for vaccination, financial barriers, vaccine stockouts, political instability and vaccine hesitancy and misinformation. ${ }^{13}$ The consistently low MCV1 coverage has led to recurrent measles outbreaks in the country. ${ }^{14}$

As we reached the end year of the Global Vaccine Action Plan 2011-2020, ${ }^{1}$ countries and international stakeholders are now developing a new strategy for accelerated progress in immunization for the upcoming decade (2021-2030): the Immunization Agenda 2030 (IA2030). Its pillars include commitment and demand, research and innovation, life course and integration, along with supply and sustainability; ${ }^{13}$ and the new agenda should serve to mobilize resources to improve vaccine coverage and equity. This is of paramount importance as low- and middle-income countries (LMICs) are now facing the unprecedented health and economic shock of the COVID-19 pandemic. $^{15}$ Furthermore, the pandemic has been associated with potentially large disruptions in the delivery of routine health services including childhood vaccines in LMICs. ${ }^{16,17}$ Economic evidence on vaccines can then be critical toward improving coverage and equity by notably informing optimal resource 
allocation across different programs. In this paper, we present a brief overview and evidence synthesis including published studies covering the topics of cost-effectiveness analysis, cost of illness associated with VPDs, equitable access to vaccines, and immunization financing in Ethiopia.

\section{METHODS}

We searched the PubMed and Google Scholar databases to source the published literature, from 2000 to 2019, on vaccine economics (evidence on immunization value, costing, financing, and efficiency that help guide health policy decisions), inequality to vaccine access (differences in vaccine access by socioeconomic characteristic or geographic location), cost of illness of VPDs (the costs, including out-ofpocket (OOP) costs, of treatment and productivity losses associated with VPDs), and immunization financing, which solely focused on the country of Ethiopia. To do so, we used various combinations of the following search terms: "vaccine"; "immunization"; "cost"; "cost of illness"; "costeffectiveness"; "financing”; "expenditure”; "pneumonia”; "diarrhea"; "measles"; "meningitis"; "hepatitis B"; "HPV"; "DPT"; "Hib”; "inequality"; "inequity”; and "Ethiopia”.

We also sourced and added secondary data from Ethiopian Demographic and Health Surveys (EDHS) and programmatic reports from Ethiopia's Federal Ministry of Health. We have only considered the literature and articles published in English and focusing on Ethiopia only. Our search for evidence was limited to an illustrative sample focused on Ethiopia. Our aim was to have a broad overview of the published literature and was not to pursue a comprehensive systematic review.

\section{RESULTS}

We identified 338 studies of which 176 were duplicates. We screened the remaining studies $(\mathrm{n}=162)$ and included 21 studies to our summary, which we detail below. Additionally, we reviewed data from five successive EDHS. ${ }^{2,8-11}$

\section{EQUITABLE ACCESS TO VACCINES}

The DHS provided the major sources of evidence on vaccine equity in Ethiopia. ${ }^{2,8-11}$ Other studies on equitable access to vaccines in Ethiopia were based on further analyses of the DHS. 3,18 Available evidence showed that disparities in immunization coverage by geographic location, wealth and maternal education levels were substantial in Ethiopia. ${ }^{2,8-11}$ According to the 2016 DHS, the coverage of fully immunized children varied from a high 89\% in Addis Ababa City Administration (an entirely urban population) to a low $15 \%$ in the Afar region (with predominantly pastoralist communities) (Figure 2). Similarly, disparities in full immunization coverage varied considerably by maternal education status, from a low $31 \%$ among mothers with no education to a high $72 \%$ among mothers with more than secondary education; and according to household wealth quintile, from $19 \%$ in the poorest quintile to $58 \%$ in the richest quintile. Yet, a study based on the 2005 and 2011 DHS showed a pro-poor change for MCV1 coverage, with

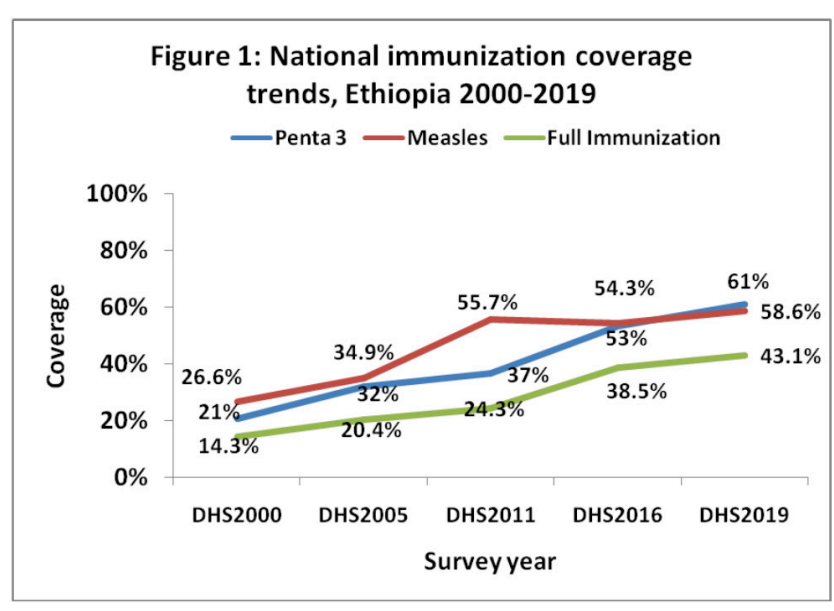

Figure 1. Trends in national immunization coverage, Ethiopia, 2000-2019. Selected indicators: measles vaccine (MCV), $3^{\text {rd }}$ dose of DPT-hepB-Hib vaccine (Penta 3), and coverage of fully immunized 12-23 month-olds (Full immunization).

Full immunization: 12-23 month-old infants who received one dose of BCG vaccine, three doses of DPT-HepB-Hib, three doses of OPV, and one dose of MCV. Sources: Ethiopia Demographic and Health Surveys. ${ }^{2,8-11}$

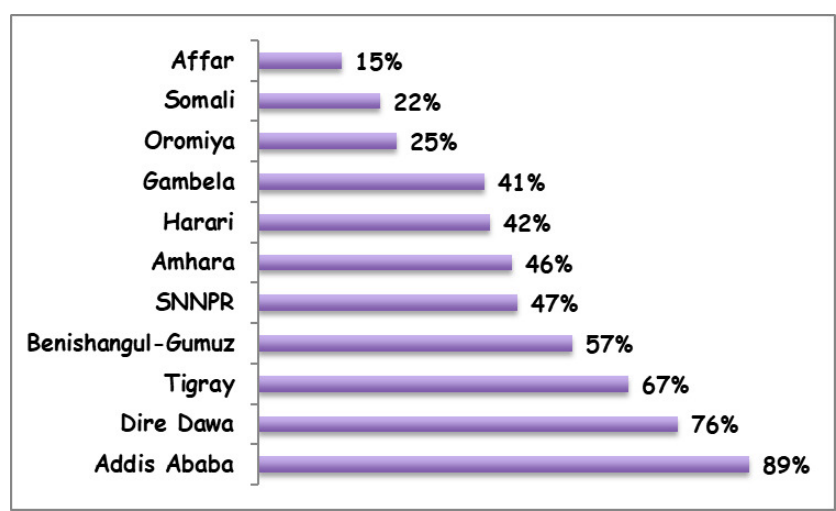

Figure 2. Regional distribution in the coverage of fully immunized 12-23 month-olds, Ethiopia, 2016.

SNNPR: Southern Nations, Nationalities, and Peoples' Region.

Source: 2016 Ethiopian Demographic and Health Survey. ${ }^{11}$

notably a lower concentration index (a commonly used metric of health disparities) in 2011 as compared to $2005 .{ }^{3}$ The concentration index for MCV1 coverage also showed a modest decrement in the 2016 DHS as compared to the 2011 DHS in Ethiopia (The concentration indices were calculated using MCV1 coverage levels among different wealth quintiles based on 2011 DHS and 2016 DHS data). ${ }^{10,11}$ Such pro-poor improvements were however not observed for the coverage of fully immunized children over the same time period. 18

\section{COST OF ILLNESS ASSOCIATED WITH VACCINE- PREVENTABLE DISEASES}

Studies on cost of illness associated with VPDs such as pneumonia (pneumococcal pneumonia), diarrhea (rotavirus diarrhea), and measles are scant in Ethiopia and we could 
Table 1. Expenditures on routine immunization services including vaccines in Ethiopia; 2015-2018.

\begin{tabular}{cllc}
\hline Year & Government (US\$) & All sources (US\$) & Percentage of government expenditures, as a share of all sources \\
\hline 2015 & $43,276,400$ & $110,246,194$ & $39.3 \%$ \\
2016 & $49,721,033$ & $121,270,813$ & $41.0 \%$ \\
2017 & $51,212,664$ & $123,696,230$ & $41.4 \%$ \\
2018 & $53,875,223$ & $126,170,155$ & $42.7 \%$ \\
\hline
\end{tabular}

Source: Federal Ministry of Health, Ethiopia. ${ }^{33}$

not identify any study that looked at indirect costs such as productivity losses. One study reported OOP medical expenses for treatment of diarrhea and pneumonia episodes in children 0-59 months. ${ }^{19}$ According to this study (which did not account for indirect costs), mean OOP expenditures per outpatient visit were estimated at $\$ 8$ for pneumonia and \$6 for diarrhea, while mean OOP expenditures per inpatient visit were estimated at $\$ 64$ for severe pneumonia and $\$ 79$ for severe diarrhea; and up to $7 \%$ of households with a case of severe pneumonia or diarrhea would be pushed below the (then) poverty threshold of $\$ 1.25$ per day (Purchasing Power Parity). ${ }^{19}$ Wealthier and urban households would face higher OOP payments, but poorer and rural households were more likely to be impoverished. ${ }^{19}$ These findings are consistent with findings from other studies in neighboring countries (e.g. Uganda and Kenya), ${ }^{20,21}$ where, in Uganda for example, the mean OOP costs (including estimates of productivity losses) for caregivers per episode of pneumonia, diarrhoea and measles had been estimated at $\$ 66, \$ 61$ and $\$ 68$, respectively.

\section{COST-EFFECTIVENESS EVIDENCE}

Similar to cost of illness of VPD, cost-effectiveness analysis (CEA) studies of health interventions were generally scarce in Ethiopia, especially with respect to vaccines. We could point to CEA evidence for tetanus toxoid vaccine (TTV) for pregnant women, RV, PCV, and MCV. ${ }^{22-28}$ A cost-effectiveness study of TTV for pregnant women to prevent neonatal tetanus as part of other maternal and neonatal health interventions found that it was highly cost-effective (incremental cost-effectiveness ratio of $\$ 168$ per disability-adjusted life year (DALY) averted) in an Ethiopian setting. ${ }^{22}$ Other studies for Ethiopia included extended cost-effectiveness analyses (ECEA). ${ }^{23-28}$ For example, ECEAs of RV and PCV 23,24 showed that both would lead to substantial decreases in under-five deaths and provide households with financial protection from the risk of OOP medical expenditures related to disease treatment. Another study of the childhood PCV program in Ethiopia for the year 2013 found incremental cost-effectiveness of around $\$ 400$ per DALY averted. ${ }^{29}$ In addition, modeling studies ${ }^{27,28}$ in Ethiopia (and in $\mathrm{LMICs}^{30}$ ) have found measles immunization to be one of the most cost-effective interventions with large returns on investment. Lastly, some studies have pointed to the potentially pro-poor benefits of vaccine programs in Ethiopia, yielding health and financial risk protection gains among the poorest households. ${ }^{31,32}$

\section{IMMUNIZATION FINANCING IN ETHIOPIA}

Financing for routine immunization services has shown modest improvements in Ethiopia over recent years prior to the COVID-19 pandemic. Such financing (from all sources of financing, i.e. from domestic, private, international sources, etc.) grew from nearly $\$ 110$ million in 2015 to more than $\$ 126$ million in 2018. Over this time period, the corresponding share of government expenditures rose from about 39 to $43 \%$ (Table 1 ). ${ }^{33}$ When only considering expenditures for vaccines (without health system delivery costs), we could observe increases in government expenditures over time, with an increase from 14\% in 2015 to $16 \%$ in 2018. In Ethiopia, Gavi, the Vaccine Alliance, would subsidize most of the vaccine costs. ${ }^{34}$

When we turned to comparing disease burden and financing resource envelopes in Ethiopia (Table 2), ${ }^{35,36}$ we saw, for example, that HIV/AIDS and other sexually transmitted diseases (STDs), along with malaria seemed to receive a greater share of health expenditures in comparison to their relative disease burden.

\section{DISCUSSION}

Coverage of immunization services has steadily expanded in Ethiopia over the last two decades but substantial gaps have remained in both level and distribution of that coverage among different segments of the population. The overall low immunization coverage with marked heterogeneity by geographic location has resulted in frequent outbreaks of VPDs like measles in Ethiopia. ${ }^{14}$ This is particularly important as the cost of the response to measles outbreaks can be quite substantial. According to a study that assessed an outbreak response of 5257 reported cases in Ethiopia's Keffa zone (Southern Nations, Nationalities, and Peoples' region), the economic cost was estimated at around $\$ 800,000$ (about $\$ 150$ per measles case). ${ }^{37}$ In contrast, the cost of delivering measles vaccine was estimated at less than $\$ 2$ per child immunized. ${ }^{38}$

Despite its low coverage, measles vaccination seemed to have seen pro-poor improvements in the past in Ethiopia. ${ }^{18}$ Such improvement in MCV1 coverage might be related to supplemental immunization activities (SIAs) that were initiated in 2002 in Ethiopia. ${ }^{14}$ Albeit the fact that SIAs could expand the reach of immunized children and help avert outbreaks, they may carry substantially higher costs as compared to routine immunization activities, and may impact on the functioning of routine immunization services and lo- 
Table 2. Comparison of disease burden and health expenditures for selected disease areas in Ethiopia (year 2017)

\begin{tabular}{llrl}
\hline Disease category & Disease burden (\% of total DALY) & Expenditures (US\$) & \% of total health expenditures \\
\hline HIV/AIDS and other STDs & $4.4 \%$ & $273,513,000$ & $8.8 \%$ \\
Tuberculosis & $3.8 \%$ & $66,560,100$ & $2.2 \%$ \\
Malaria & $0.5 \%$ & $249,481,800$ & $8.1 \%$ \\
Major non-communicable diseases & $27.5 \%$ & $372,000,000$ & $12.0 \%$ \\
Vaccine-preventable conditions $^{*}$ & $4.2 \%$ & $123,696,230$ & $4.0 \%$ \\
\hline
\end{tabular}

"The disease burden estimate for vaccine-preventable conditions does not account for vaccine-preventable pneumonia (pneumococcal pneumonia), diarrhea (rotavirus diarrhoea), tuberculosis and cervical cancer burdens.

DALYs = disability-adjusted life years.

Sources: Federal Ministry of Health, Ethiopia; ${ }^{33,36}$ Institute for Health Metrics and Evaluation..$^{35}$

cal health systems. ${ }^{39-41}$

The key toward high and equitable immunization coverage is ensuring sustainable financing. Immunization expenditures in Ethiopia have improved substantially with a corresponding growth in government expenditures. Still, more than $57 \%$ of immunization services are financed from external sources. The 2018 expenditures were approximately \$125 million, which was less than an estimated \$164-295 million required to provide universal vaccination for the Ethiopian birth cohort (We made such estimates based on the 2018 Ethiopian birth cohort, the cost of fully vaccinating a child (\$25-45) and accounting for health system costs (nearly half of the total cost per child)). ${ }^{42}$ Comparison of disease burden with associated health expenditures showed that other disease areas (e.g.HIV/AIDS, malaria) would receive proportionally more funding than VPDs in Ethiopia (Table 2). More than $80 \%$ of HIV/AIDS spending and nearly $50 \%$ of malaria spending in Ethiopia came from development assistance for health. ${ }^{43}$

Our report has several important limitations and presents a number of caveats. First, we intend to provide here a brief overview of the published literature and articles on Ethiopia. Our search for evidence was limited to an illustrative sample focused on Ethiopia. Our aim was to have a broad overview of the published literature and was not to pursue a comprehensive systematic review. Second, as a result, the findings should be interpreted with caution, and one should not draw firm recommendations from this report. Rather, despite these limitations, our study presents a brief overview and evidence synthesis including published studies covering the topics of CEA, cost of illness associated with VPDs, equitable access to vaccines, and immunization financing in Ethiopia. In sum, it highlights some of the evidence gaps in the Ethiopian vaccine economics literature that would be valuable to be addressed in the future.

IA2030 envisions "A world where everyone, everywhere, at every age, fully benefits from vaccines for good health and well-being." 13 The IA2030 vision tries to address the challenges of the past decade and the changing context with major focuses on sustaining trust in vaccines, bridging inequity in vaccine access either among or within countries, addressing migrants and cross-border population movements, conflict and political instability, emerging disease outbreaks, ensuring immunization for all ages and maintenance of quality vaccine supplies. Without addressing these challenges, it will be difficult to achieve the IA2030 vision particularly in sub-Saharan Africa and Ethiopia.

Expanding equitable access to vaccines could not only save lives and avert illnesses but also help advance economic development. In LMICs, the return on investment on vaccines for every dollar spent was estimated at multiple times the costs depending on whether cost of illness or value of statistical life approaches were used. ${ }^{44}$ The Ministerial Conference on Immunization in Africa hosted in 2016 in Addis Ababa had reaffirmed universal immunization coverage as a cornerstone for health and development on the continent. ${ }^{45}$ The declaration highlighted the importance of increasing and sustaining domestic investments and funding allocations, including innovative financing mechanisms for immunization services. ${ }^{42}$ In the last decade, Ethiopia has seen a substantial economic development and now aspires to be a middle-income country by $2025 .{ }^{46}$ Along with economic development, its government envisions to attain population health status commensurate with the best performing middle-income countries by $2025 .{ }^{46}$ Realization of such ambitious targets will likely require the government's commitment towards more resource allocations for sustainable vaccine financing in Ethiopia.

\section{ACKNOWLEDGEMENTS}

We thank the Maternal and Child Health Directorate, Federal Ministry of Health, Ethiopia and its participants to a vaccine economics workshop held in Addis Ababa (January 2020), which prompted the realization of this study. We are grateful to Tewodaj Mengistu for valuable comments on an earlier version of the manuscript.

\section{FUNDING}

This work was funded by Gavi, the Vaccine Alliance. The funder had no role in the design, conduct and analysis of the study or approval and decision to submit the manuscript for publication. The views expressed are those of the authors and not necessarily those of the funder.

\section{AUTHORSHIP CONTRIBUTIONS}

STM and SV initiated the study. STM wrote the first draft of 
the manuscript. All authors contributed to writing and editing of the manuscript.

\section{COMPETING INTERESTS}

The authors completed the Unified Competing Interest form at www.icmje.org/coi_disclosure.pdf (available upon request from the corresponding author), and declare no conflicts of interest.

\section{CORRESPONDENCE TO}

Dr. Solomon Tessema Memirie, M.D., Ph.D.

P.O.Box: 121260

Nifas Silk Lafto, Addis Ababa, Ethiopia

Submitted: November 08, 2020 GMT, Accepted: February 01, 2021 GMT 


\section{REFERENCES}

1. World Health Organization. Global Vaccine Action Plan: 2011-2020. World Health Organization; 2013.

2. Ethiopian Public Health Institute (EPHI) and ICF. Ethiopia Mini-Demographic and Health Survey 2019: Key Indicators. EPHI and ICF International; 2019.

3. Memirie ST, Verguet S, Norheim OF, Levin CE, Johansson KA. Inequalities in utilization of maternal and child health services in Ethiopia: The role of primary health care. BMC Health Serv Res.

2016;16(1):51. doi:10.1186/s12913-016-1296-7

4. World Health Organization, World Bank. Tracking Universal Health Coverage: 2017 Global Monitoring Report. World Health Organization and World Bank; 2017.

5. The World Bank. Data: Ethiopia. Published online 2020. Accessed June 8, 2020. https://data.worldbank.0 $\mathrm{rg} /$ country/ethiopia

6. Ethiopia Public Health Training Initiative. Expanded Program in Immunization: For the Ethiopian Health Center Team. Gondar University College; 2002. Accessed January 31, 2020. https://www.cartercente r.org/resources/pdfs/health/ephti/library/modules/De gree/Mod_Exp_Imm_final.pdf

7. World Health Organization. WHO vaccinepreventable diseases: Monitoring system. 2019 global summary. Published online 2019. Accessed January 31, 2020. https://apps.who.int/immunization_monitor ing/globalsummary/countries?countrycriteria\%5Bcou ntry\%5D\%5B\%5D=ETH

8. Central Statistical Authority [Ethiopia] and ORC Macro. Ethiopia Demographic and Health Survey 2000. Central Statistical Authority and ORC Macro; 2001.

9. Central Statistical Agency [Ethiopia] and ICF International. Ethiopia Demographic Health Survey 2005. Addis Ababa and Calverton Maryland: Central Statistics Agency and ICF International; 2006.

10. Central Statistical Agency [Ethiopia] and ICF International. Ethiopia Demographic Health Survey 2011. Central Statistics Agency and ICF International; 2012.

11. Central Statistical Agency [Ethiopia] and ICF International. Ethiopia Demographic Health Survey 2016. Central Statistics Agency and ICF International; 2016.
12. Federal Democratic Republic of Ethiopia Ministry of Health. Health Sector Transformation Plan 2015/ 2016-2019/2020. Federal Ministry of Health; 2015. Accessed February 3, 2020. https://ehia.gov.et/sites/d efault/files/Resources/HSTP\%20Final\%20Print\%2020 15-11-27\%20Print\%20size.pdf

13. Immunization Agenda 2030. World Health Organization; 2018. Accessed July 7, 2020. https://ww w.who.int/immunization/immunization_agenda_203 0/en/

14. Akalu HB. Review on measles situation in Ethiopia: past and present. Journal of Tropical Diseases. 2015;4(2). doi:10.4172/2329-891x.1000193

15. International Monetary Fund. World Economic Outlook: A Long and Difficult Ascent.; 2020. Accessed January 4, 2021. https://www.imf.org/en/Publication s/WEO/Issues/2020/09/30/world-economic-outlook-o ctober-2020

16. Abbas K, Procter SR, Zandvoort KV, et al. Routine childhood immunization during the COVID-19 pandemic in Africa: A benefit-risk analysis of health benefits versus excess risk of SARS-CoV-2 infection. Lancet Glob Health. 2020;8(10):e1264-e1272. doi:10.1 016/s2214-109x(20)30308-9

17. Ahmed SAKS, Ajisola M, Azeem K, et al. Impact of the societal response to COVID-19 on access to healthcare for non-COVID-19 health issues in slum communities of Bangladesh, Kenya, Nigeria and Pakistan: Results of pre-COVID and COVID-19 lockdown stakeholder engagements. BMJ Glob Health. 2020;5(8):e003042. doi:10.1136/bmigh-2020-003042

18. Skaftun EK, Ali M, Norheim OF. Understanding inequalities in child health in Ethiopia: Health achievements are improving in the period 2000-2011. PLoS ONE. 2014;9(8):e106460. doi:10.1371/journal.po ne.0106460

19. Memirie ST, Metaferia ZS, Norheim OF, Levin CE, Verguet S, Johansson KA. Household expenditures on pneumonia and diarrhoea treatment in Ethiopia: A facility-based study. BMJ Glob Health. 2017;2(1):e000166. doi:10.1136/bmigh-2016-000166

20. Immunization Economics.org. Decade of Vaccine Economics: Cost of illness field studies. Accessed July 6, 2020. http://immunizationeconomics.org/dove-fs 
21. Ayieko P, Akumu AO, Griffiths UK, English M. The economic burden of inpatient paediatric care in Kenya: Household and provider costs for treatment of pneumonia, malaria and meningitis. Cost Eff Resour Alloc. 2009;7(1):3. doi:10.1186/1478-7547-7-3

22. Memirie ST, Tolla MT, Desalegn D, et al. A costeffectiveness analysis of maternal and neonatal health interventions in Ethiopia. Health Policy and Planning. 2019;34(4):289-297. doi:10.1093/heapol/czz $\underline{034}$

23. Pecenka CJ, Johansson KA, Memirie ST, Jamison DT, Verguet $S$. Health gains and financial risk protection: An extended cost-effectiveness analysis of treatment and prevention of diarrhoea in Ethiopia. BMJ Open. 2015;5(4):e006402-e006402. doi:10.1136/b miopen-2014-006402

24. Johansson KA, Memirie ST, Pecenka C, Jamison DT, Verguet S. Health gains and financial protection from pneumococcal vaccination and pneumonia treatment in Ethiopia: Results from an extended costeffectiveness analysis. PLOS ONE.

2015;10(12):e0142691.

25. Dawkins BR, Mirelman AJ, Asaria M, Johansson KA, Cookson RA. Distributional cost-effectiveness analysis in low- and middle-income countries: Illustrative example of rotavirus vaccination in Ethiopia. Health Policy and Planning. 2018;33(3):456-463. doi:10.1093/heapol/czx175

26. Verguet S, Murphy S, Anderson B, Johansson KA, Glass R, Rheingans R. Public finance of rotavirus vaccination in India and Ethiopia: An extended costeffectiveness analysis. Vaccine.

2013;31(42):4902-4910. doi:10.1016/j.vaccine.2013.0 $\underline{7.014}$

27. Verguet S, Olson ZD, Babigumira JB, et al. Health gains and financial risk protection afforded by public financing of selected interventions in Ethiopia: An extended cost-effectiveness analysis. Lancet Global Health. 2015;3(5):e288-e296. doi:10.1016/s2214-109 $\mathrm{x}(14) 70346-8$

28. Driessen J, Olson ZD, Jamison DT, Verguet S. Comparing the health and social protection effects of measles vaccination strategies in Ethiopia: An extended cost-effectiveness analysis. Social Science \& Medicine. 2015;139:115-122. doi:10.1016/j.socscime d.2015.06.018

29. Kebede TT, Svensson M, Addissie A, Trollfors B, Andersson R. Cost-effectiveness of childhood pneumococcal vaccination program in Ethiopia: Results from a quasi-experimental evaluation. BMC Public Health. 2019;19(1):1078. doi:10.1186/s12889-0 19-7423-8
30. Ozawa S, Clark S, Portnoy A, Grewal S, Brenzel L, Walker DG. Return on investment from childhood immunization in low- and middle-income countries 2011-20. Health Affairs. 2016;35(2):199-207. doi:10.13 77/hlthaff.2015.1086

31. Assebe LF, Kwete XJ, Wang D, et al. Health gains and financial risk protection afforded by public financing of selected malaria interventions in Ethiopia: An extended cost-effectiveness analysis. Malaria Journal. 2020;19(1):41. doi:10.1186/s12936-0 20-3103-5

32. Chang AY, Riumallo-Herl C, Perales NA, et al. The equity impact vaccines may have on averting deaths and medical impoverishment in developing countries. Health Affairs. 2018;37(2):316-324. doi:10.1377/hlthaf $\underline{\mathrm{f} .2017 .0861}$

33. Federal Ministry of Health Ethiopia. WHOUNICEF Joint Reporting Format (JRF) Annual Country Report, 2015-2020. Federal Ministry of Health; 2020.

34. Gavi. Ethiopia Country information. Accessed March 31, 2020. https://www.gavi.org/programmes-i mpact/country-hub/africa/ethiopia

35. Institute for Health Metrics and Evaluation (IHME). GBD Compare Data Visualization. IHME, University of Washington; 2017. Accessed March 2, 2020. https://healthdata.org/gbd-compare

36. Federal Democratic Republic of Ethiopia Ministry of Health. Ethiopia Health Accounts 2016/2017. Ministry of Health; 2019. Accessed March 12, 2020. ht tp://www.moh.gov.et/ejcc/sites/default/files/2020-01/ Ethiopia\%207th\%20Health\%20Accounts\%20Report_2 016-17.pdf

37. Wallace AS, Masresha BG, Grant G, et al. Evaluation of economic costs of a measles outbreak and outbreak response activities in Keffa Zone, Ethiopia. Vaccine. 2014;32(35):4505-4514. doi:10.101 6/j.vaccine.2014.06.035

38. Griffiths UK, Korczak VS, Ayalew D, Yigzaw A. Incremental system costs of introducing combined DTwP-hepatitis B-Hib vaccine into national immunization services in Ethiopia. Vaccine. 2009;27(9):1426-1432. doi:10.1016/j.vaccine.2008.1 2.037

39. Hanvoravongchai P, Mounier-Jack S, Oliveira Cruz $\mathrm{V}$, et al. Impact of Measles Elimination Activities on Immunization Services and Health Systems: Findings From Six Countries. The Journal of Infectious Diseases. 2011;204:S82-S89. doi:10.1093/infdis/iir091 
40. Chakrabarti A, Grépin KA, Helleringer S. The impact of supplementary immunization activities on routine vaccination coverage: An instrumental variable analysis in five low-income countries. PLoS ONE. 2019;14(2):e02102049. doi:10.1371/journal.pon e. 0212049

41. Verguet S, Jassat W, Bertram MY, et al. Impact of supplemental immunisation activity (SIA) campaigns on health systems: Findings from South Africa.

Journal of Epidemiology and Community Health. 2013;67(11):947-952. doi:10.1136/jech-2012-202216

42. Mihigo RM, Okeibunor JC, O’Malley H, Masresha $\mathrm{B}$, Mkanda P, Zawaira F. Investing in life saving vaccines to guarantee life of future generations in Africa. Vaccine. 2016;34(48):5827-5832. doi:10.1016/ j.vaccine.2016.06.036
43. Federal Democratic Republic of Ethiopia Ministry of Health. The Ethiopia Sixth Health Accounts, 2013/ 14: Statistical Report. Addis Ababa, Ethiopia; 2017. Accessed January 4, 2021. https://www.hfgproject.or g/ethiopia-sixth-health-accounts-201314-statisticalreport/

44. Decade of Vaccine Economics (DoVE). The value of vaccine programs: Highlights from the DoVE study. Accessed May 23, 2020. https://vaccineroi.org/

45. World Health Organization. Addis Declaration on Immunization: Status of Immunization in Africa 2016. Accessed July 6, 2020. https://www.afro.who.int/healt h-topics/immunization/the-addis-declaration-immu nization

46. Admasu K, Tamire A, Tsegaye S. Envisioning the future of the health sector: An update. Federal Democratic Republic of Ethiopia Ministry of Health Quarterly Health Bulletin. 2014;6:3-12. 